\title{
Functional and Metabolic Effects of Cardioplegia Induced by a Young's Solution (YNG Solution) as Assessed in Isolated Atrial Preparations and in Isolated Perfused Heart Preparations of the Guinea Pig
}

\author{
Tomie Kawada, B.S., Hatsushi Shimomura, M.S., \\ Yoshio Kajtwara, M.S., Seiichiro Yoshida, Ph.D., and \\ Shoichi ImaI, M.D., Ph.D.*
}

\section{Summary}

The protective effects of Young's solution (YNG solution), a cardioplegic solution, on the myocardial function and metabolism were assessed in isolated atrial preparations and isolated perfused heart preparations of the guinea pig. In atrial preparations, the time to arrest of the contraction became shorter as the concentrations of the $\mathrm{K}^{+}, \mathrm{Mg}^{++}$, and $\mathrm{K}_{-}^{+} \mathrm{Mg}^{++}$solutions increased, while the time to resumption of the contraction was lengthened. There was no difference in the time to arrest between $\mathrm{K}^{+}$and $\mathrm{K}^{+}-\mathrm{Mg}^{++}$ solutions, but the time to resumption was reduced with $\mathrm{K}^{+-} \mathrm{Mg}^{++}$ solution to about half the value with $\mathrm{K}^{+}$solution. YNG solution represented an optimum solution for obtaining a quick cardiac arrest and quick resumption of contraction. In the isolated perfused heart, the time to arrest was similar for all the cardioplegic solutions used and the heart stopped in diastole. However, the time to arrest was longer with cold Krebs-Henseleit's solution (cold cardioplegia). The time to resumption of the contraction was the shortest with YNG solution, which yielded the highest mitochondrial respiratory control ratio (RCR) and $\mathrm{ADP} / \mathrm{O}$ ratio. There was a negative correlation between the time to resumption of contraction and mitochondrial $\mathrm{RCR}$ or $\mathrm{ADP} / \mathrm{O}$ ratio $(\mathrm{r}=-0.50$ and -0.58 , respectively).

\section{Additional Indexing Words:}

Myocardial protection Cardioplegic solution Myocardial function Mitochondrial respiratory activity Coronary flow

From the Research Laboratories, Ohta Pharmaceutical Co., Ltd., Saitama 332, Japan.

* Department of Pharmacology, Niigata University School of Medicine, Niigata.

Received for publication December 25, 1982.

Manuscript revised May 23, 1983. 
$\mathbf{I}^{\mathrm{N}}$ 1955 Lam et $\mathrm{al}^{1 /}$ and Melrose et $\mathrm{al}^{2)}$ used high potassium solution to induce a quick arrest of the heart beat necessary for open heart surgery. Later, Young et $\mathrm{al}^{3}$ introduced a mixture of potassium, magnesium and neostigmine, i.e. Young's solution, which resulted in a quicker recovery of the cardiac function after operation. At about the same time as the introduction of Young's solution selective cardiac hypothermia was adopted for myocardial protection. Shumway's original method ${ }^{4)}$ consisted in the topical cooling, while Mundth et al,5) Tyers et $\mathrm{al}^{6 /}$ and Stemmer et al ${ }^{7}$ induced cardiac hypothermia by perfusion of the coronary arteries with cold Ringer solution. Recently in Japan Wada et al $^{11}$ combined the two methods and have obtained excellent results in myocardial protection during operation. The cardioplegic solution they used for cold perfusion was a Young's solution without neostigmine. The present paper pertains to the critical evaluation of efficacy of the Young's (YNG) solution as a cardioplegia. The effects of changing the concentration of $\mathrm{K}^{+}$and $\mathrm{Mg}^{++}$on the time to the cardiac arrest and the resumption of the contractions were studied in isolated atrial preparations of the guinea pig. In addition, the effect on the recovery process after cardiac arrest were studied in the isolated perfused heart preparations of the same animal in comparison with that of the cold cardioplegia and correlated with the effects on the respiratory activity of the myocardial mitochondria. Although Young et al already studied the effects of $\mathrm{K}^{+}$and $\mathrm{Mg}^{++}$ solutions on the process of cardiac arrest and recovery, the concentration ranges they tested were limited, and no attempt was made to assess the mitochondrial activities.

\section{Materials and Methods}

1. Isolated atrial preparation

Male guinea pigs weighing between 400-600 Gm were stunned by a blow on the head. The heart was rapidly excised, atria were isolated and placed in an organ bath containing $10 \mathrm{ml}$ of Krebs-Henseleit's solution maintained at a temperature of $32 \pm 0.5^{\circ} \mathrm{C}$ and aerated with $95 \% \quad \mathrm{O}_{2}+5 \% \quad \mathrm{CO}_{2}$. One end of the atrial preparation was fixed to the bottom of the bath, while the other end was connected to a force-displacement transducer (Nihon Kohden SB1T), under a resting tension of $0.5 \mathrm{Gm}$. The tension development was recorded on an ink-writing oscillograph with a carrier amplifier (Nihon Kohden RP-5). The rate of contraction was recorded with a cardiotachometer (Nihon Kohden RT-5). After equilibration, the bathing solution was changed to a cardioplegic solution $\left(32 \pm 0.5^{\circ} \mathrm{C}\right)$ and the time to the complete arrest of the contraction was monitored. One or $5 \mathrm{~min}$ after the 
arrest, the bathing solution was changed to Krebs-Henseleit's solution and the time to resumption of the contraction was recorded. The protocol of the experiments is depicted in Fig. la.

2. Isolated perfused heart preparation

a) Assessment of cardiac function

Guinea pigs of either sex weighing from 300 to $600 \mathrm{Gm}$ were stunned by a blow on the head. The heart was quickly excised and retrograde perfusion through the aorta by Langendorff's method was started with modified Krebs-Henseleit's solution ( $\mathrm{NaCl}, 123.9 \mathrm{mM}$; KCl, $4.7 \mathrm{mM}$; $\mathrm{CaCl}_{2}, 2.5 \mathrm{mM}$; $\mathrm{MgSO}_{4}, 1.2 \mathrm{mM} ; \mathrm{KH}_{2} \mathrm{PO}_{4}, 1.2 \mathrm{mM} ; \mathrm{NaHCO}_{3}, 24.9 \mathrm{mM}$; glucose, $5.5 \mathrm{mM}$; sodium pyruvate, $2.0 \mathrm{mM}$ ) kept at a temperature of $38 \pm 0.5^{\circ} \mathrm{C}$ and aerated with a gas mixture of $95 \% \mathrm{O}_{2}+5 \% \mathrm{CO}_{2}$. The perfusion pressure was set at $75 \mathrm{~cm} \mathrm{H} \mathrm{H}_{2} \mathrm{O}$. A cannulating type probe of an electromagnetic flowmeter (Nihon Kohden MF 26) placed just before the aortic cannula measured the coronary inflow. The heart rate was counted with a cardiotachometer triggered by phasic changes of the coronary inflow.

After 1 hour's equilibration period, the perfusion solution was changed to a cardioplegic solution at $10 \pm 1{ }^{\circ} \mathrm{C}$ and the time to the arrest of contraction, the temperature of the perfusion solution and the coronary inflow at the time of the cardiac arrest were recorded. Then, the preparation was perfused for 1 hour with Krebs-Henseleit's solution $\left(10 \pm 1^{\circ} \mathrm{C}\right)$ under arrest of the contraction. In another group of the preparations, cardiac arrest was induced with Krebs-Henseleit's solution at $10 \pm 1^{\circ} \mathrm{C}$ (cold cardioplegia). The perfusion of the preparation was continued for 1 hour after the arrest. After

a)

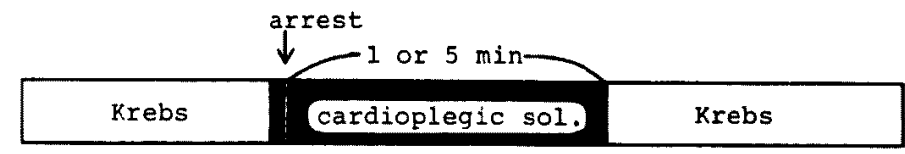

b)

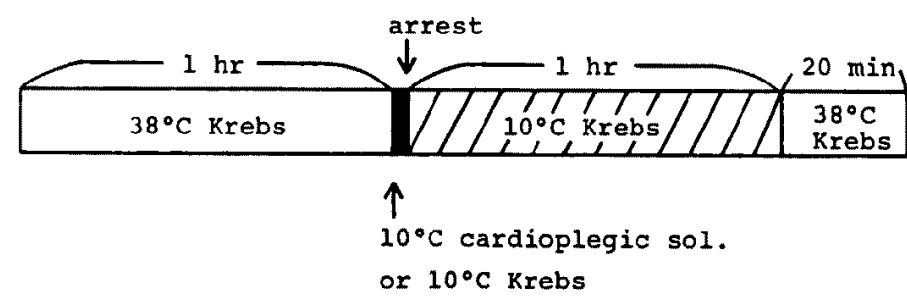

Fig. 1. Experimental protocol, a) Isolated atrial preparations, b) Isolated perfused heart preparations. 
1 hour's perfusion with cold Krebs-Henseleit's solution, the perfusion medium was changed to a warm Krebs-Henseleit's solution $\left(38 \pm 0.5^{\circ} \mathrm{C}\right)$ and the time to resumption of the contraction was recorded. The perfusion was continued for $20 \mathrm{~min}$ to see whether the preparation recovered regular contractions. The protocol is depicted in Fig. 1b.

b) Assessment of mitochondrial function

After 20 mins' reperfusion with Krebs-Henseleit's solution of $38^{\circ} \mathrm{C}$, the heart was removed from the perfusion system and mitochondrial preparations were made following the method of Hagiwara.9) Ventricular muscles were minced and 10 volumes of the preparation solution (mannitol, $0.21 \mathrm{M}$; sucrose, $0.07 \mathrm{M}$; EDTA-Na, $0.25 \mathrm{mM}$; Tris-HCl buffer ( $\mathrm{pH} 7.4), 10 \mathrm{mM}$ ) precooled to a temperature below $4^{\circ} \mathrm{C}$ were added. Five $\mathrm{mg} / \mathrm{Gm}$ wet weight of alkaline protease (crystal, $100 \times 10^{4} \mathrm{PUN}$, Nagase Sangyo) was added to this solution. After 20 mins' incubation at $0^{\circ} \mathrm{C}$, the preparation was washed throughly with cold preparation solution and homogenized with a teflon homogenizer at $0^{\circ} \mathrm{G}$. The homogenate was centrifuged at $600 \mathrm{~g}$ for $10 \mathrm{~min}$ at $0^{\circ} \mathrm{C}$, and the resultant supernatant was then centrifuged at $10,000 \mathrm{~g}$ for $10 \mathrm{~min}$. The pellet was resuspended with a small volume of cold preparation solution and centrifuged again at $600 \mathrm{~g}$ for $3 \mathrm{~min}$. The supernatant was centrifuged at $10,000 \mathrm{~g}$ for $10 \mathrm{~min}$. The pellet was resuspended in a reaction medium of the following composition: mannitol, $0.25 \mathrm{M}$; EDTA-Na, $0.2 \mathrm{mM}$; KCl, $10 \mathrm{mM} ; \mathrm{KH}_{2} \mathrm{PO}_{4}, 10 \mathrm{mM}$; Tris-HCl buffer ( $\mathrm{pH} 7.4$ ), $10 \mathrm{mM}$. The oxygen consumption of the mitochondria was measured with a polarographic apparatus (Yanagimoto PO-100A), using $l$-glutamic acid as a substrate and ADP as a phosphate acceptor. The oxygen consumption rate of the state 3 and 4 , respiratory control ratio ( $\mathrm{RCR}$ ) and $\mathrm{ADP} / \mathrm{O}$ ratio were obtained to assess respiratory activity. Protein determinations were conducted following Lowry's method. ${ }^{10)}$

Cardioplegic solutions used in the present study were as follows:

YNG solution: $0.8 \% \mathrm{~K}_{3}\left(\mathrm{C}_{6} \mathrm{H}_{5} \mathrm{O}_{7}\right) \cdot \mathrm{H}_{2} \mathrm{O}$

$-2.46 \% \mathrm{MgSO}_{4} \cdot 7 \mathrm{H}_{2} \mathrm{O}$ in saline,

$\mathrm{K}^{+}-\mathrm{Mg}^{++}$solution: $0.2-6.4 \% \quad \mathrm{~K}_{3}\left(\mathrm{C}_{6} \mathrm{H}_{5} \mathrm{O}_{7}\right) \cdot \mathrm{H}_{2} \mathrm{O}$

$-2.46 \% \mathrm{MgSO}_{4} \cdot 7 \mathrm{H}_{2} \mathrm{O}$ in saline,

$\mathrm{K}^{+}$solution: $0.2-6.4 \% \quad \mathrm{~K}_{3}\left(\mathrm{C}_{6} \mathrm{H}_{5} \mathrm{O}_{7}\right) \cdot \mathrm{H}_{2} \mathrm{O}$ in saline,

$\mathrm{Mg}^{++}$solution: $0.62-19.7 \% \mathrm{MgSO}_{4} \cdot 7 \mathrm{H}_{2} \mathrm{O}$ in saline.

\section{RESULTS}

1) Atrial preparation

Representative records of the changes in the atrial contractions induced 
by cardioplegic solutions are shown in Fig. 2. One min after complete cessation of contractions (arrest), the solution was changed to Krebs-Henseleit's solution.
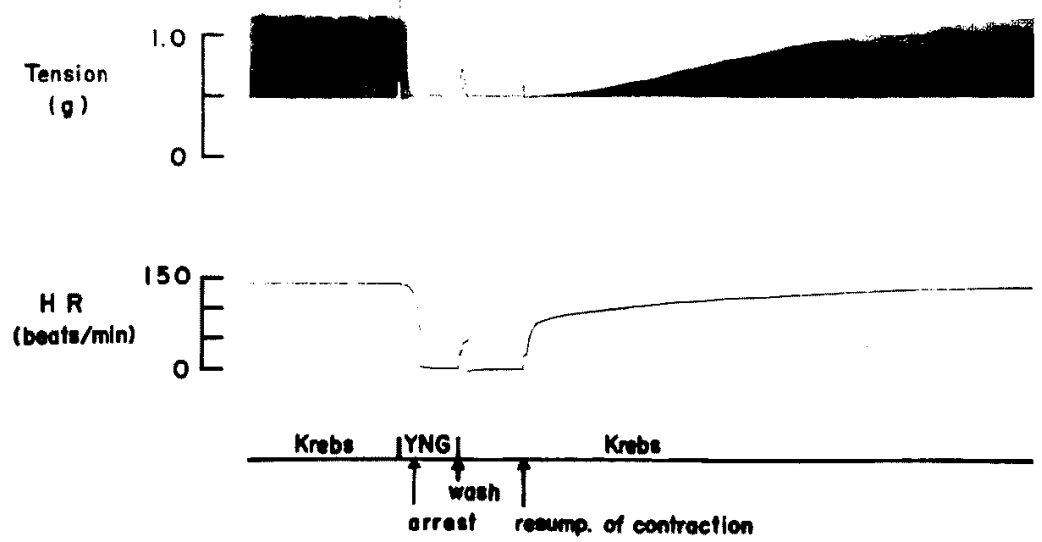

Fig. 2. Effects of YNG solution on the isolated atrial preparation. As shown in the figure, the time of the resumption of contractions was clearly dis. cernible by a definite contraction which was followed by small, but gradually increasing contractions.

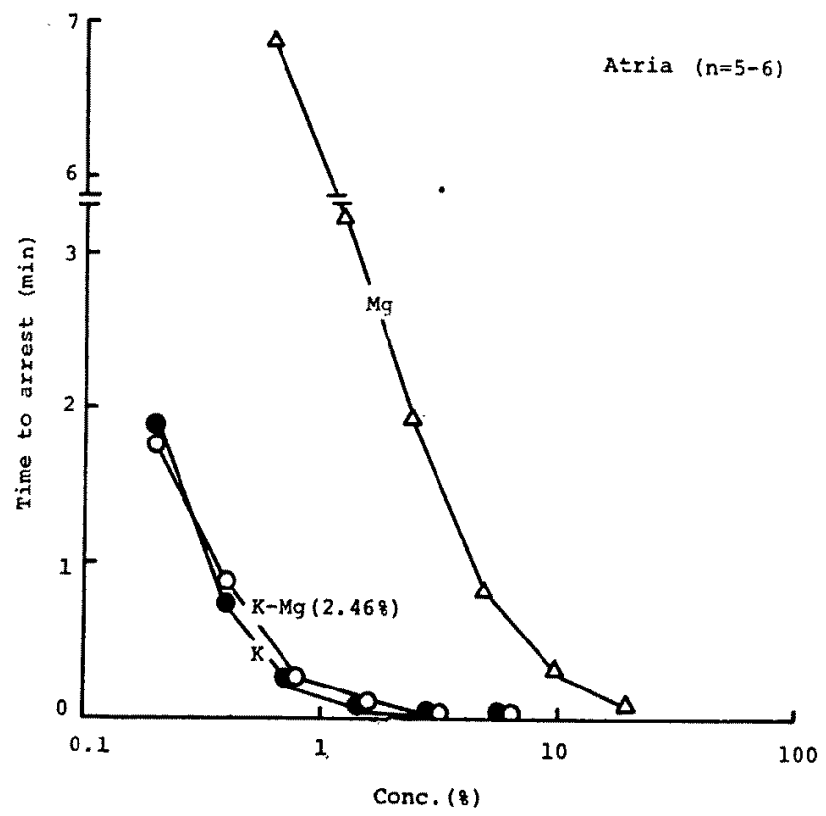

Fig. 3. Relationship between the time to arrest and ionic concentrations of cardioplegic solution in isolated guinea pig atrial preparations. 


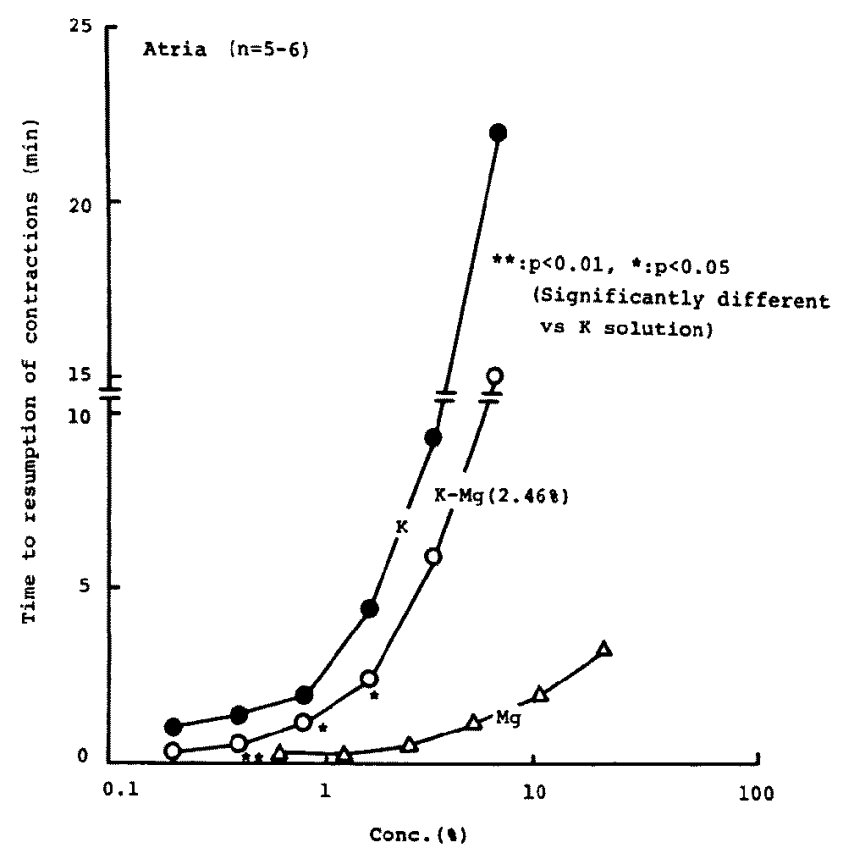

Fig. 4. Relationship between the time to resumption of the contraction and the ionic concentrations of cardioplegic solution in isolated atrial preparations, after immersion in cardioplegic solutions for $1 \mathrm{~min}$ to induce arrest of contractions.

As shown in Fig. 3, the time to arrest of contraction decreased as the ionic concentrations of the cardioplegic solution were increased. There was no difference between the $\mathrm{K}^{+}$solution and the $\mathrm{K}^{+-} \mathrm{Mg}^{++}$solution, while the time to arrest was longer with the $\mathrm{Mg}^{++}$-solution as compared with either the $\mathrm{K}^{+}$or $\mathrm{K}^{+-} \mathrm{Mg}^{++}$solutions.

As shown in Fig. 4, the time to resumption of contractions in KrebsHenseleit's solution after a 1 min incubation with cardioplegic solutions increased with increased concentrations of either solution. However, the addition of magnesium tended to decrease the resumption time by about $50 \%$. The resumption times for $\mathrm{K}^{+-} \mathrm{Mg}^{++}$solutions containing $0.4,0.8$ (YNG solution) and $1.6 \% \mathrm{~K}^{+}$were significantly shorter than for $\mathrm{K}^{+}$solutions of the corresponding concentrations, and the time to resumption for $\mathrm{Mg}^{++}$solutions was shorter than for $\mathrm{K}^{+}$solutions or $\mathrm{K}^{+}-\mathrm{Mg}^{++}$solutions. The same holds true for the time to resumption of the contraction after a 5 min incubation in cardioplegic solutions. After resumption of contractions, the preparation contracted regularly without abnormal contractions.

Fig. 5 depicts the relationship between the time to arrest and the time to resumption of contractions after 5 mins' incubation in cardioplegic solutions. As compared with the corresponding $\mathrm{K}^{+}$solutions, $\mathrm{K}^{+-} \mathrm{Mg}^{++}$solutions of 0.8 


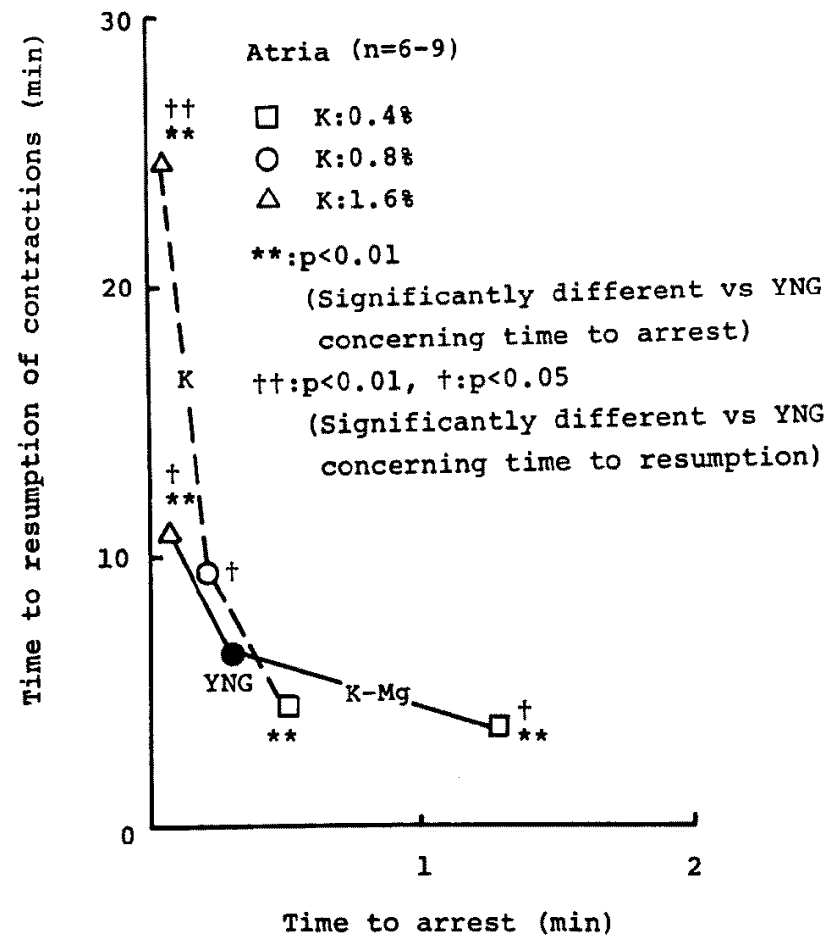

Fig. 5. Relationship between the time to arrest and the time to resumption of contractions in isolated atria placed in cardioplegic solutions for $5 \mathrm{~min}$ to induce the arrest of contraction.

and $1.6 \%$ significantly reduced the time to resumption without changing the time to arrest of contractions. As compared with YNG solution, the time to resumption of the contraction was significantly longer with the 0.8 and $1.6 \%$ $\mathrm{K}^{+}$solutions or the $1.6 \% \mathrm{~K}^{+-} \mathrm{Mg}^{++}$solution, while the time to arrest was significantly longer with the $0.4 \% \mathrm{~K}^{+}$or $0.4 \% \mathrm{~K}^{+}-\mathrm{Mg}^{++}$solutions. Thus, it was possible to obtain the fastest arrest and quickest resumption of the contraction of the atrial preparations with YNG solution.

2) Isolated perfused heart

(a) Cardiac function

As listed in Table I, the time to arrest of contractions with YNG solution was $1.19 \mathrm{~min}$. The time to arrest tended to be longer with the $0.4 \% \mathrm{~K}^{+}$$\mathrm{Mg}^{++}$solution and the $2.46 \% \mathrm{Mg}^{++}$solution. The time necessary for arrest without cardioplegic solution (i.e. with cold Krebs-Henseleit's solution) was $6.07 \mathrm{~min}$, a time which was significantly longer than with cardioplegic solutions. The temperature of the perfusion medium flowing out of the preparation at arrest was significantly lower with the $0.4 \% \mathrm{~K}^{+}-\mathrm{Mg}^{++}$and $2.46 \%$ $\mathrm{Mg}^{++}$solutions, compared with $22^{\circ} \mathrm{C}$ recorded with the $1.6 \% \mathrm{~K}^{+}-\mathrm{Mg}^{++}$and 
Table I. The Effects of Cardioplegic Solutions on Cardiac Function

\begin{tabular}{|c|c|c|c|c|c|c|}
\hline \multirow[b]{2}{*}{ Function } & \multicolumn{6}{|c|}{ Treatment } \\
\hline & $\begin{array}{c}0.8 \% \mathrm{~K}- \\
\mathrm{Mg} \\
(\mathrm{YNG})\end{array}$ & $\begin{array}{c}0.4 \% \mathrm{~K}- \\
\mathrm{Mg}\end{array}$ & $\begin{array}{c}1.6 \% \mathrm{~K}- \\
\mathrm{Mg}\end{array}$ & $0.8 \% \mathrm{~K}$ & $2.46 \% \mathrm{Mg}$ & $\begin{array}{c}\text { Cold } \\
\text { car- } \\
\text { dioplegia }\end{array}$ \\
\hline Time to arrest $(\mathrm{min})$ & $\begin{array}{l}1.19 \pm \\
0.10\end{array}$ & $\begin{array}{l}1.58 \pm \\
0.43\end{array}$ & $\begin{array}{l}0.99 \pm \\
0.13\end{array}$ & $\begin{array}{l}0.91 \pm \\
0.13\end{array}$ & $\begin{array}{l}2.56 \pm \\
0.87\end{array}$ & $\begin{array}{l}6.07 \pm \\
1.15^{* * *}\end{array}$ \\
\hline Temp, at arrest $\left({ }^{\circ} \mathrm{C}\right)$ & $\begin{array}{c}22.0 \pm \\
1.7\end{array}$ & $\begin{array}{r}17.0 \pm \\
0.8^{*}\end{array}$ & $\begin{array}{c}22.0 \pm \\
1.3\end{array}$ & $\begin{array}{l}19.8 \pm \\
0.4\end{array}$ & $\begin{array}{r}16.4 \pm \\
0.7 *\end{array}$ & $\begin{array}{r}11.0 \pm \\
0.4^{* *}\end{array}$ \\
\hline $\begin{array}{l}\text { Max. coronary flow after arrest } \\
{[\% \text { change from controla }]}\end{array}$ & $243 \pm$ & $\begin{array}{c}192 \pm \\
9\end{array}$ & $\frac{221 \pm}{16} \pm$ & $\begin{array}{c}215 \pm \\
9\end{array}$ & $\begin{array}{c}188 \pm \\
37\end{array}$ & $\begin{aligned} 137 \pm \\
22 * *\end{aligned}$ \\
\hline $\begin{array}{l}\text { Time to resumption of contrac- } \\
\text { tions (min) }\end{array}$ & $\begin{array}{l}2.20 \pm \\
0.24\end{array}$ & $\begin{array}{l}2.54 \pm \\
0.36\end{array}$ & $\begin{array}{l}3.15 \pm \\
0.79\end{array}$ & $\begin{array}{l}3.54 \pm \\
0.48^{*}\end{array}$ & $\begin{array}{l}3.70 \pm \\
0.61^{*}\end{array}$ & $\begin{array}{l}3.02 \pm \\
0.29\end{array}$ \\
\hline $\begin{array}{l}\text { Time to resumption of regular } \\
\text { contractions (min) }\end{array}$ & $\begin{array}{l}11.78 \pm \\
1.17\end{array}$ & $\begin{array}{l}11.13 \pm \\
1.09\end{array}$ & $\begin{array}{l}10.91 \pm \\
1.32\end{array}$ & $\begin{array}{l}13.13 \pm \\
1.54\end{array}$ & $\begin{array}{l}13.22 \pm \\
2.20\end{array}$ & $\begin{aligned} 11.21 \pm \\
0.47\end{aligned}$ \\
\hline $\begin{array}{l}\text { Resumption of regular contrac- } \\
\text { tions }(\%)\end{array}$ & 100 & 60 & 100 & 80 & 40 & 80 \\
\hline
\end{tabular}

YNG solutions.

The temperature at arrest with cold Krebs-Henseleit's solution $\left(11^{\circ} \mathrm{C}\right)$ was significantly lower than those with cardioplegic solutions. These findings were in agreement with the lengthening of the time necessary for the arrest of contractions. With the $0.4 \% \mathrm{~K}^{+}-\mathrm{Mg}^{++}$and $2.46 \% \mathrm{Mg}^{++}$solutions, a sporadic resumption of contractions was seen in several instances after a temporary arrest of contractions.

The coronary flow immediately after the arrest was twice the control value in preparations arrested with cardioplegic solution, while the increase was small in preparations arrested with cold Krebs-Henseleit's solution (significantly less than those obtained with cardioplegic solution, except for the $2.46 \% \mathrm{Mg}^{++}$solution).

The time to resumption of contractions (2.2 $\mathrm{min}$ ) was shortest with YNG solution. It increased in the order of $0.4 \% \mathrm{~K}+-\mathrm{Mg}^{++}$solution, cold cardioplegia and $1.6 \% \mathrm{~K}^{+-} \mathrm{Mg}^{++}$solution. The values obtained with $0.8 \% \mathrm{~K}^{+}$ solution $\left(3.45 \mathrm{~min}\right.$ ) and $2.46 \% \mathrm{Mg}^{++}$solution $(3.70 \mathrm{~min}$ ) were significantly larger than with YNG solution.

The time to resumption of regular contractions was slightly longer with $0.8 \% \mathrm{~K}^{+}$and $2.46 \% \mathrm{Mg}^{++}$solutions than with YNG solution, although the difference was not significant. Although the percentage of preparations where regular contractions resumed within 20 min was $100 \%$ with YNG solution and $1.6 \% \mathrm{~K}^{+-} \mathrm{Mg}^{++}$solution, it was $80 \%$ with $0.8 \% \mathrm{~K}^{+}$solution and cold cardioplegia, $60 \%$ with $0.4 \% \mathrm{~K}^{+}-\mathrm{Mg}^{++}$solution and $40 \%$ with $2.46 \%$ 
$\mathrm{Mg}^{++}$solution.

(b) Respiratory activity of the mitochondria

The respiratory control ratio (RCR) and $\mathrm{ADP} / \mathrm{O}$ ratio of the mitochondrial preparations obtained from hearts arrested with cardioplegic solutions or cold Krebs-Henseleit's solution and reperfused for 20 min with Krebs-Henseleit's solution at $38^{\circ} \mathrm{C}$ are illustrated in Fig. 6 . The values obtained with

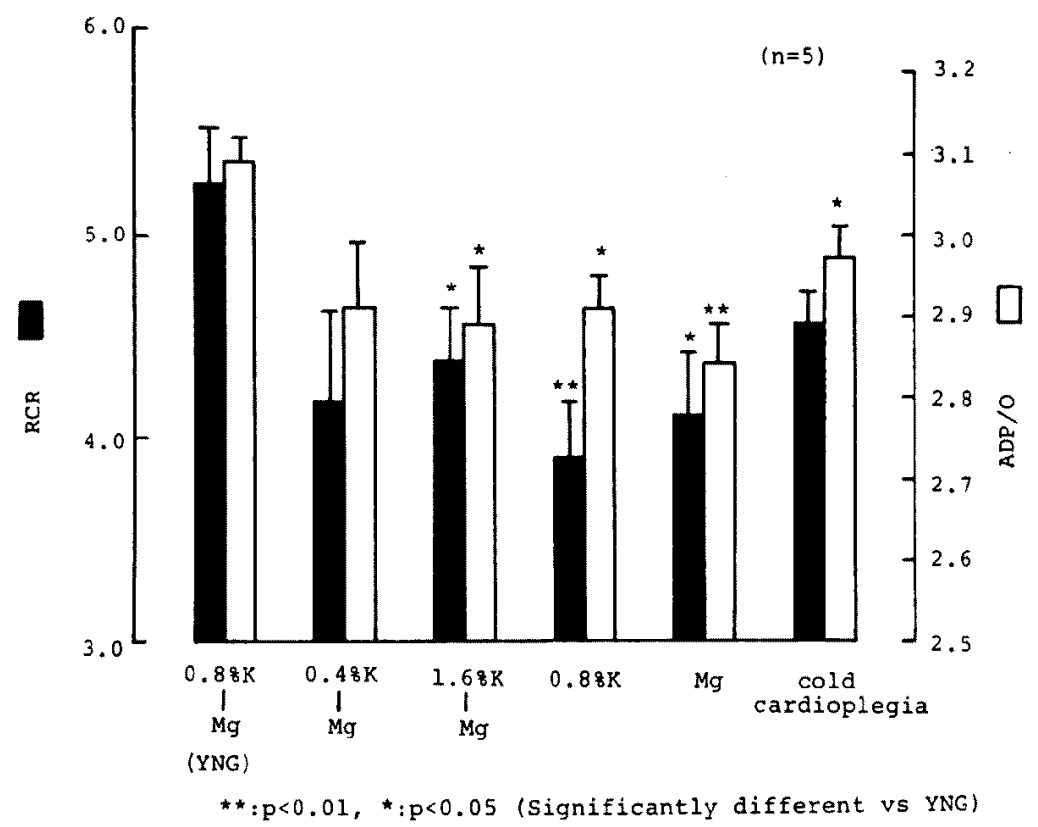

Fig. 6. Effects of cardioplegic solutions on the mitochondrial function.

Vertical lines indicate the S.E.
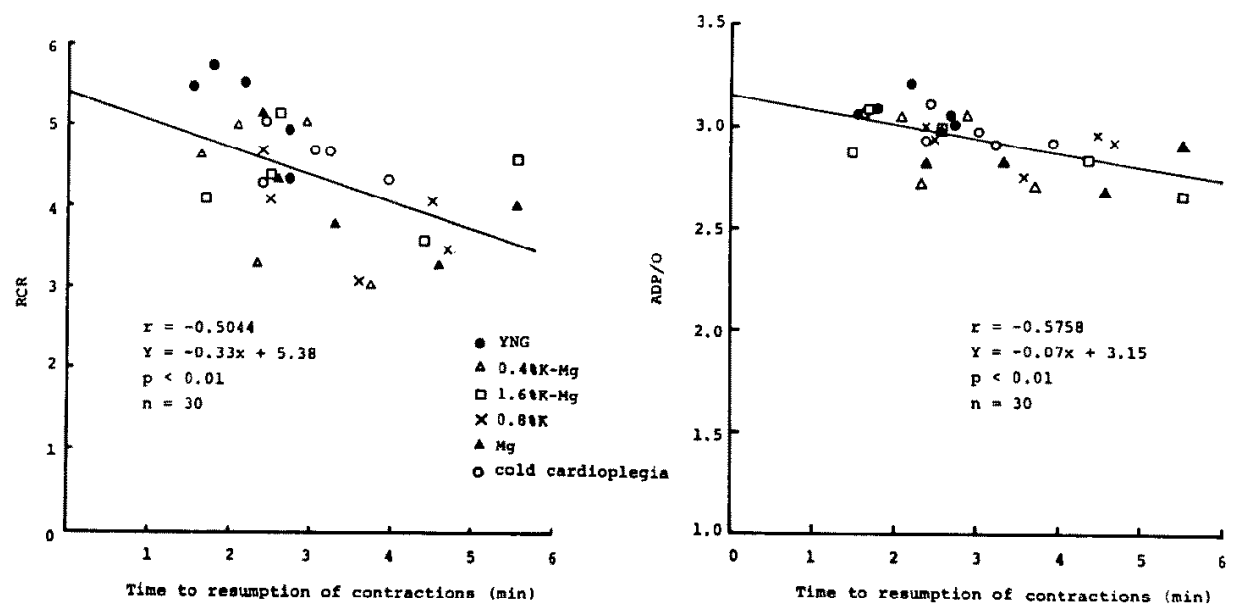

Fig. 7. Effects of cardioplegic solutions on the correlation between the time to resumption of contractions and the values of RCR and the ADP/O ratio. 
YNG solution were significantly higher than those obtained from the hearts arrested with other cardioplegic solutions or cold Krebs-Henseleit's solution, except for the values of RCR (4.18) and ADP/O ratio (2.91) obtained from the hearts arrested with $0.4 \% \mathrm{~K}^{+} \mathrm{Mg}^{++}$solution and the value of RCR (4.56) obtained from the hearts arrested with cold Krebs-Henseleit's solution. These values were also lower than those with YNG solution but the differences were not significant.

(c) The relationship between the time to resumption of cardiac function and mitochondrial respiratory activity

As shown in Fig. 7, there was a significant correlation between the mitochondrial $\mathrm{RCR}$ and $\mathrm{ADP} / \mathrm{O}$ ratio and the time to resumption of the contraction after reperfusion, indicating a dependence of the resumption of cardiac function on mitochondrial respiratory activity.

\section{Discussion}

According to Young et $\mathrm{al}^{3)}$ and Merrit et $\mathrm{al}^{11)}$ the ideal cardioplegic solution must satisfy the following criteria:

(1) a quick and complete cardiac arrest,

(2) a complete absence of electrical as well as contractile activities at the time of cardiac arrest,

(3) minimum metabolic effects,

(4) a quick resumption of the normal beat after reperfusion,

(5) no ventricular fibrillation or any other serious arrhythmias,

(6) no systemic toxicity.

Using isolated, perfused cat heart preparations, they tested the effects of several solutions on the process of cardiac arrest and recovery of regular beats and selected a mixture of $0.81 \% \mathrm{~K}^{+}$and $2.47 \% \mathrm{Mg}^{2+}$, i.e. Young's solution, as the best cardioplegic solution. Chiba et $\mathrm{al}^{12)}$ reported satisfactory protection of the left ventricular function and myocardial metabolism during 2 hours of aortic clamping with intermittent cold perfusion of the myocardium, using a modified Young's solution $\left(\mathrm{K}_{3}\left(\mathrm{C}_{6} \mathrm{H}_{5} \mathrm{O}_{7}\right) \mathrm{H}_{2} \mathrm{O}, 0.8 \% ; \mathrm{MgSO}_{4} 7 \mathrm{H}_{2} \mathrm{O}, 2.46 \%\right.$; $\mathrm{NaHCO}_{3}, 0.021 \% ; \mathrm{NaCl}, 0.4 \%$ ) as a cardioplegic solution. They concluded that the rapid production of the diastolic arrest and the resultant reduction of energy consumption produced by a modified Young's solution contributed to protection of the myocardial metabolism (and function).

The present study confirmed the superiority of $\mathrm{YNG}$ solution to $\mathrm{K}^{+}$or $\mathrm{Mg}^{++}$solutions or $\mathrm{K}^{+}-\mathrm{Mg}^{++}$solutions of different compositions both in the isolated heart muscle preparation and in the isolated perfused heart. Although no significant differences were observed between the isolated perfused 
hearts arrested with YNG solution and those arrested with cold Krebs-Henseleit's solution with regard to either the time to resumption of contractions or the mitochondrial RCR, the time to arrest of contractions was markedly shorter and the mitochondrial $\mathrm{ADP} / \mathrm{O}$ ratio was higher with $\mathrm{YNG}$ solution. Furthermore, the coronary flow recorded immediately after the arrest was greater with YNG solution than with the cold cardioplegia, suggesting that a more complete relaxation of the cardiac muscle was obtained with YNG solution. Thus, it may be inferred that the cardioplegia achieved with YNG solution is superior to that obtained with $\mathrm{K}^{+}$and $\mathrm{Mg}^{++}$solutions alone, with $\mathrm{K}^{+}-\mathrm{Mg}^{++}$solution of different compositions, and with cold Krebs-Henseleit's solution. This conclusion is in agreement with the findings of Ishikawa ${ }^{13}$ ) that the cardiac arrest with YNG solution resulted in a better recovery than with cold cardioplegia. A better recovery with YNG solution was also reported by Kitamura ${ }^{14}$ ) and Shimazu et al, ${ }^{15)}$ who ascribed it to an induction of quick diastolic arrest and a resultant better irrigation of the myocadium, which in turn brought about a quicker cooling of the myocardium.

It is conceivable that both $\mathrm{K}^{+}$and $\mathrm{Mg}^{++}$play important roles in the protective action of YNG solution. The presence of a high concentration of $\mathrm{K}^{+}$ is responsible for a rapid induction of diastolic cardiac arrest, while the presence of $\mathrm{Mg}^{++}$inhibits myocardial metabolism. ${ }^{16)} \quad$ It seems that the presence of citrate is not critical for the protection, since Merrit et al ${ }^{11}$ found no difference in the cardioplegic action of $\mathrm{KCl}$ and potassium citrate. Better preservation of mitochondrial respiratory activity may be a reflection of the protective effects of the rapid cardioplegia and the better irrigation of the myocardium. This is in agreement with a better preservation of the high energy phosphate compounds reported by several previous researchers. ${ }^{12,17)-19)}$

\section{REFERENCES}

1. Lam CR, Geoghegan T, Lepore A: Induced cardiac arrest for intracardiac surgical procedures. J Thorac Surg 30: 620, 1955

2. Melrose DG, Dreyer B, Bentall HH, Baker JBE: Elective cardiac arrest. Lancet 2: 21, 1955

3. Young WG Jr, Sealy WC, Brown IW Jr, Hewitt WC Jr, Callaway HA Jr, Merrit DH, Harris JS: A method for controlled cardiac arrest as an adjunct to open heart surgery. J Thorac Surg 32: 604, 1956

4. Shumway NE, Lower RR: Topical cardiac hypothermia for extended periods of anoxic arrest. Surg Forum 10: 563, 1959

5. Mundth ED, Sokol DM, Levine FH, Austen WG: Evaluation of methods for myocardial protection during extended periods of aortic cross-clamping and hypoxic cardiac arrest. Bull Soc Int Chir 4: 227, 1970

6. Tyers GFO, Hughes HCJ Jr, Todd GJ, Williams DR, Andrew EJ, Prophet GA, Waldhausen JA: Protection from ischemic cardiac arrest by coronary perfusion with cold Ringer's lactate solution. J Thorac Cardiovasc Surg 67: 411, 1974 
7. Stemmer EA, MacCart P, Stanton WW, Thibault W, Dearden LS, Collolly JE: Functional and structural alterations in the myocardium during aortic cross-clamping. $J$ Thorac Cardiovasc Surg 66: 754, 1973

8. Wada J, Natsuaki M, Nakae S, Nagara H, Oteki H, Kato M, Kitamura N, Hashimoto A: Clinical evaluation for the effects of cold cardioplegic solution on myocardial protection. Effects of combined use of Young's solution and GIK solution. J Jpn Assoc Thorac Surg 28: 1099,1980

9. Chance B, Hagiwara B: Direct spectroscopic measurements of interaction of components of the respiratory chain with adenosine triphosphate (ATP), adenosine diphosphate (ADP), phosphate, and uncoupling agents. Proc 5th Intern Congr Biochem, Moscow, Pergamon Press, Intracellular Respiration 5: 3, 1963

10. Lowry $\mathrm{OH}$, Rosebrought NJ, Farr AL, Randall RJ: Protein measurement with the Folin phenol reagent. J Biol Chem 193: 265, 1951

11. Merrit DH, Sealy WC, Young WG Jr, Harris JS: Potassium, magnesium, and neostigmine for controlled cardioplegia. Evaluation with the isolated perfused cat heart. AMA Arch Surg 76: 365, 1958

12. Chiba M, Abe T: Studies of myocardial protection for hypertrophied left ventricle. Effect of combined methods of modified Young's and $4^{\circ} \mathrm{C}$ Ringer's lactate solution. J Jpn Assoc Thorac Surg 28: 1840,1980

13. Ishikawa $S$ : Experimental study on the method of cardiac resuscitation after prolonged circulatory interruption under deep hypothermia. J Jpn Assoc Thorac Surg 14: 1097, 1966

14. Kitamura N, Natuaki M, Nagae H, Hakae S, Shimazu K, Ishihara K, Wada J: Experimental study of myocardial protective factors and clinical evaluation of the GIK solution for cardioplegia. J Jpn Assoc Thorac Surg 27: 467, 1979

15. Shimazu $\mathrm{K}$, Ishihara $\mathrm{K}$, Kitamura $\mathrm{N}$, Wada J: Comparative study of various technique of myocardial cooling. Jpn J Thorac Surg 31 : 677, 1978

16. Nakae S, Wabb WR, Salyer KE, Unal MO, Cook WA, Dodds RP, Williams GT: Extended survival of the normothermic anoxic heart with metabolic inhibitors. Ann Thorac Surg 3: 37,1967

17. Levinsky S, Merchant FJ, Feinberg H: Effects of KCl-induced cardiac arrest on energy metabolism and contractility of ischemic dog heart. Fed Proc 33: 398, 1974

18. Hearse DJ, Stewart DA, Chain EB: Recovery from cardiac bypass and elective cardiac arrest. The metabolic consequences of various cardioplegic procedures in the isolated rat heart. Circulat Res 35: 448, 1974

19. Hearse DJ, Stewart DA, Braimbridge MV: Hypothermic arrest and potassium arrest. Metabolic and myocardial protection during elective cardiac arrest. Circulat Res 36: 481, 1975 